\title{
Intervention in Overweight Children Improves Body Mass Index (BMI) and Physical Activity
}

\author{
Violet Siwik, MD, Randa Kutob, MD, MPH, Cheryl Ritenbaugh, PhD, MPH, \\ Luis Cruz, MD, MPH, Janet Senf, PhD, Mikel Aickin, PhD, Scott Going, PhD, \\ and Andrew Shatte, PhD
}

Background: Childhood obesity is a growing epidemic in family medicine with few clinical treatment options. We implemented and evaluated a group office-visit intervention by family physicians for overweight children and their parents, emphasizing nutrition and physical activity within a resiliency psychosocial model.

Methods: The intervention lasted for 3 months, with half of the children crossing over to intervention after 6 months in the study. Participants included 35 children who met eligibility criteria of being in third through fifth grades and having a body mass index (BMI) above the 85th percentile. The 3-month, 12-session intervention, "Choices," included topics on nutrition, physical activity, and resiliency. The sessions were developed for delivery by a family physician and a nutritionist who received training in positive psychology and resilience skills. Main outcome measures were BMI $z$ scores for age and sex and $z$ scores for weight by age and sex, as well as qualitative interviews to understand individual and family processes.

Results: The intervention resulted in a significant effect on one primary outcome, BMI $z$ score $(-0.138$ per 9 months $[P=.017])$ and a trend toward significance on the weight for age $z$ score $(-0.87$ per 9 months $[P=.09])$. The net shift of activity from the low metabolic equivalents (METs) to the high METs had an intervention effect of 2.84 METs $(P=.037)$. Families reported lasting changes in behaviors and attitudes.

Discussion: The innovative approach used in this study demonstrated modest efficacy in reducing BMI $z$ score, changing physical activity levels, and possibly shifting family dynamics. (J Am Board Fam Med 2013;26:126-137.)

Keywords: Child Nutrition, Family Health, Intervention, Obesity, Overweight, Sedentary Lifestyle

Childhood obesity is an emerging epidemic; two thirds of adults ${ }^{1}$ and nearly one third of children are overweight or obese. ${ }^{2}$ Obese children are more likely

This article was externally peer reviewed.

Submitted 7 May 2012; revised 24 September 2012; accepted 8 October 2012.

From the Department of Family and Community Medicine (VS, RK, CR, MA), University of Arizona College of Medicine (JS), Tucson (VS, RK, CR); the American Medical Center, Upper Tumon, Guam (LC); Department of Nutritional Sciences, Center for Physical Activity and Nutrition, University of Arizona, Tucson (SG); and the University of Arizona, Tucson (AS).

Funding: Support was provided by National Institutes of Health grant R21 HD50962.

Conflict of interest: none declared.

Corresponding author: Violet P. Siwick, Department of Family and Community Medicine, University of Arizona College of Medicine, 707 N. Cherry Ave., Tucson, AZ 85719 (E-mail: vsiwik@email.arizona.edu). to become obese adults. ${ }^{3,4}$ Adult obesity is associated with a number of serious health conditions including heart disease, diabetes, and some cancers. ${ }^{5}$ Research on the mediators of familial patterns of overweight children and obesity suggests that overweight parents tend to create environments that promote overweight among their children. ${ }^{6}$

Several public health initiatives have been launched to address this problem. ${ }^{7}$ However, family physicians have an important role in timely identification of overweight and obese children during periodic health examinations. They also have a role in promoting preventive measures, encouraging positive changes in behavior, as well as identifying and treating obesity-related comorbidities. $^{8}$ They are uniquely situated to counsel both children and their parents. 
Highly controlling and restrictive parental feeding strategies contribute to positive energy balance and higher body mass index (BMI) by interfering with children's ability to self-regulate energy intake. ${ }^{6,9}$ Because parents provide the child's contextual environment, they should be viewed as key players and central agents of change in the prevention and treatment of weight-related problems and therefore should be provided with appropriate training. ${ }^{10}$ Practical advice for parents includes how to foster children's preferences for healthy foods and how to promote acceptance of new foods by children.

Reviews of childhood obesity prevention studies focus largely on school-based programs, many of which do not include a parent component. ${ }^{11,12}$ Our review of the literature in PubMed, performed in 2010, identified 88 publications that dealt with childhood obesity interventions. Few of these interventions involved both parent and child. ${ }^{13,14}$ No studies combined motivational interviewing or similar interventions with structured physical activity, nutritional education, or both.

When designing this intervention, we reviewed the literature on strategies previously proven effective for weight loss in children. Based on the review, we selected approaches that empowered participants to make informed "choices" related to nutrition, television viewing, intake of sugar-sweetened beverages and fast food, and physical activity. To improve coping skills and increase the likelihood of success in making lifestyle changes, we enhanced the concept of "choices" by providing an innovative approach to problem-solving skills designed to strengthen resiliency. We developed a group office curriculum and conducted an earlyphase trial to test the efficacy of the program using a lagged intervention/control design.

\section{Methods}

The University of Arizona Human Subjects Protection Program approved all procedures. Parents provided written consent, and children provided written assent for the intervention and data collection.

\section{Design}

The intervention lasted for 3 months, with half of the children crossing over to intervention after 6 months in the study. In this 3-month lagged inter- vention design, the cohort periods were March through May 2006 and September through November 2006. Both cohorts had data collection at months $0,3,6,9,12$, and 15 . Cohort 1 began the intervention at study month 0 , continued the intervention until month 3 , and had data collected after the intervention at months $6,9,12$, and 15 . Cohort 2 was the lagged control and began the intervention in study month 6, completed it in month 9 , and had data collection in months 12 and 15 . Allocation was done using design-adaptive allocation that minimizes the differences between groups as participants enter the study. Balancing factors were sex, age, and BMI. ${ }^{15}$

\section{Target Population and Recruitment}

The intervention targeted children in third through fifth grades (ages 8-11 years, BMI above the 85 th percentile) and their parents. Recruitment methods included posters and flyers in family medicine, pediatric, and community clinics; university E-mail listserves; campus-wide notices; newspaper advertisements; and news stories between December 2005 and February 2006 (Figure 1).

\section{Intervention}

The Choices model incorporated the inclusion of a parent and built on the above-described literature review and motivational interviewing/enhancement philosophy. ${ }^{14}$ Rather than requiring participants to follow a regimented, "one size fits all" approach, Choices allowed participants to modify their lifestyle individually in relationship to their goals. The facilitators consistently avoided labeling choices as good or bad, healthy or unhealthy. The interven-

\section{Figure 1. Choices consort diagram.}

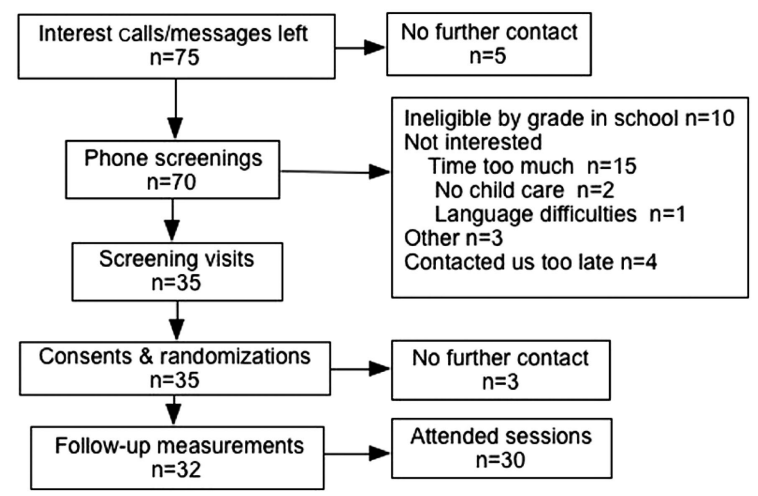


tion encouraged choices based on factual knowledge (Table 1).

The 12-week group office visit intervention was developed to be compatible within a fee- for-service family medicine environment. Groups met weekly from 5:30 to 7:00 PM and were organized into 3, 20- to 30-minute increments: individual and group check-in; class content; and physical activity. Standardized participant handouts and leader manuals were developed covering the entire intervention so that both cohorts received the same intervention. Parents met with the family physician attending and the nutritionist, while the boys and girls met separately with the family medicine residents for the specific topic of the week; everyone came together for the physical activity. Both parents and their children received age-appropriate information about the same topics. The family medicine residents presented the nutrition and activity material in an engaging, interactive manner to encourage the children's participation. The children's groups met separately to meet their ageappropriate developmental and gender issues. After the final session, each group had reunions 3 to 4 and 6 to 8 months after intervention.

\section{Physical Activity and Nutrition}

In session one, children and a parent received pedometers, and instructions on their use. They re- ported steps in the second session, and set goals to increase their total steps. Physical activities promoted individual and group participation with small toys, such as a soft soccer ball, a dance video, and children's yoga cards. As sessions progressed, children became conditioned and activities became more vigorous.

The program adapted a TV turn-off concept from Robinson et $\mathrm{al}^{13}$ Over several sessions, children observed their TV behavior and then committed to a TV turn-off challenge; parents committed to support them. Children who met their goals received a certificate of accomplishment.

The nutrition content was developed by the authors and nutritionist and focused on: benefits of water consumption; decreasing sugar-sweetened beverages; understanding satiety and portion sizes; familiarity with fat content in foods and choices for lower fat fast foods.

\section{Resiliency and Self-Talk}

The psychosocial goal was to empower children and parents to recognize their choices. Dr. Andrew Shatte, a psychologist with expertise in the concept of resiliency, provided a 2-day training session for the group facilitators. He taught the following concepts: (1) our thoughts about problems impact our feelings; and (2) changing our thoughts about situations can change our emotional and behavioral

\section{Table 1. Choices Classes Intervention Topics}

\begin{tabular}{|c|c|c|}
\hline Class & Content and Objectives & Physical Activity (PA) \\
\hline 1 & Get acquainted; learn about the program (why and what); pedometers & $\begin{array}{l}\text { Pedometers: using, logging; } \\
\text { family activity }\end{array}$ \\
\hline \multirow{5}{*}{2} & Orientation to importance for children's health; need for whole family to be involved & Guide \\
\hline & How active am I? What's fun? How can I do more? Why is it important? & \\
\hline & $\begin{array}{l}\text { Barriers and facilitators to family PA, child's PA; enhancing PA for all; pedometer } \\
\text { goals }\end{array}$ & Pedometer challenge \\
\hline & What are the connections between cognition and emotion and behavior? & \multirow{2}{*}{$\begin{array}{l}\text { Chalk for hopscotch and } \\
\text { sidewalk games }\end{array}$} \\
\hline & $\begin{array}{l}\text { Between what I think and what I feel and do? How does this work for children? } \\
\text { Adults? }\end{array}$ & \\
\hline 4 & Why is it important to drink water for thirst? How much sugar is in beverages? & Jump ropes \\
\hline 5 & $\begin{array}{l}\text { How can I challenge my thinking habits that do not help me? Recognize inaccurate } \\
\text { thinking and change it? Ways to support children and family }\end{array}$ & Nerf soccer \\
\hline 6 & How much food is enough? Portion sizes & Frisbee \\
\hline 7 & Television: when more is not better; the TV turn-off challenge & TV turn-off \\
\hline 8 & Time in the park: family games and review & Yoga cards \\
\hline 9 & Fast foods: the truth about fat in food & Dance video \\
\hline 10 & Fast foods: making other choices for the long term & Juggling scarves \\
\hline 11 & Making active choices: living my life & TaiBo video \\
\hline \multirow[t]{2}{*}{12} & Choosing food and beverage that fits my lifestyle: putting it all together & \\
\hline & Celebration/graduation & \\
\hline
\end{tabular}


response. We developed teaching materials and training manuals for 2 resilience-focused sessions and educated the family medicine residents on this topic as well as the topics for the other sessions.

"Resilience" was the psychological framework for fostering flexibility and accuracy in making new choices. The greatest obstacle to resilience is inaccurate thoughts and beliefs about oneself, one's world, and one's future. People tend to fall into predictable thinking traps, limiting their problemsolving abilities. By analyzing traps and providing steps to circumvent them, participants gain accuracy in their thinking and increase resilience. ${ }^{14}$ Dr. Shatte has applied this approach previously to treat and prevent depression. The model was adapted here because of its relevance to children's beliefs about obesity, their behaviors, and themselves in relation to peers.

\section{Quality Assurance Measures}

All classes and reunions were audio-recorded and reviewed weekly to refine the model and language used by all the intervention staff. The leaders and investigators debriefed after each session to discuss how to improve future sessions. We systematically gathered participant feedback to modify the intervention process and contribute to process evaluation in upcoming sessions.

\section{Measures}

Quantitative Measures

Outcome measures were collected at baseline and every 3 months for up to 15 months. The main outcome quantitative measures were BMI- and weight-for-age $z$ scores as well as percent body fat. Height was measured using a wall-mounted stadiometer; the average of 3 measurements was used. Weight and percent body fat were measured on an electronic scale with built-in bioelectric impedance (Tanita, Arlington Heights, IL); 2 measurements were taken, and if inconsistent a third was obtained. Reference population data from the Centers for Disease Control and Prevention were used for $z$ scores. ${ }^{16}$

\section{Physical Activity}

Data collection sessions occurred 5:30 to 7:30 PM on Tuesday through Thursday. At each data collection visit, the children were given a validated physical activity recall focused on recalling activities before, during, and after school of the current and previous day. A metabolic equivalent (MET; a unit describing the energy expenditure of a specific activity) was assigned to each activity. Examples include watching television or playing video games (1 MET) and running (10 MET), according to the validated measurement protocol. Although self-reports have the potential for bias, this type of recall is appropriate to the age group and has been used and validated in a multisite, school-based obesity intervention study for this age group. ${ }^{17} \mathrm{We}$ chose it instead of pedometers to lower the ongoing study burden for participant. Pedometers were used as an intervention tool, and did not contribute to the outcome measures.

\section{Qualitative Interviews}

All parents and their children were contacted for 30-minute qualitative interviews 12 to 18 months and again at 18 to 24 months after intervention. Sex-matched interviewers met the children individually. Initial questions were open-ended and regarded recall of the intervention; probes on the easiest, most difficult, and continuing lifestyle changes followed. Parents were queried about project content (Choices model, thinking patterns), changes in children's behavior, and the durability of those changes. Interviews were recorded digitally.

\section{Data Analysis}

\section{Quantitative Measures}

All outcome variables were analyzed using the same statistical model, a generalized linear regression with a 1-period stationary autoregressive structure within person (xtgee procedure of Stata). The explanatory factors were (1) count of the number of measurement periods since the start of intervention to measure the cumulative intervention effect and set to 0 for the last 2 measurements in cohort 1 and the first 2 measurements in cohort 2; (2) count of the total number of 3-month (measurement) periods being studied to account for physical growth; and (3) baseline value of the outcome measure. Analyses were adjusted for 2 of the factors used in the dynamic allocation: sex and BMI at baseline; the omitted variables were ethnicity (because of a lack of variability) and age at baseline (because of an intercorrelation with baseline weight, BMI, or height). Thus, the intervention effects were assessed from the start of the intervention (month 0 in cohort 1 , month 6 in cohort 2 ) over the subse- 
quent 9 months. The analyses were supplemented with graphic analysis to avoid regression artifacts. Missing data for weight and height were imputed by linearly interpolating for any missing data in visits 2 to 5 (4 missing of 128 possible visits [2.3\%]) and linearly extrapolated based on standardized growth curves if visit 6 was missing (5 missing of 32 total visits $[15.6 \%[)$. All values were rechecked before analysis. A time trend variable was included to control for normal growth. $P$ values for weight and BMI endpoints were 1-sided because of the research hypotheses of improvement, not worsening, but the height $P$ values were 2 -sided because of an absence of a 1-sided research hypothesis.

The original planned sample size was 40 , with $80 \%$ power to detect an effect size of 0.7 to 0.8 using a simple conditional change model. The sample size reported here is 32 but includes more measurement visits per person than anticipated in the original power calculations. The observed effect sizes were 0.47 for the target $4 \mathrm{~kg}$ /year weight effect and 0.52 for the target $0.75 \mathrm{~kg} / \mathrm{m}^{2}$ per year BMI effect.

\section{Qualitative Data Analysis}

All recordings were transcribed and coded using Atlas.ti (ATLAS.ti Scientific Software Development GmbH, Berlin, Germany). Codes included those prespecified based on interview questions and open codes developed on emerging themes. Prespecified codes included attitudes toward the Choices concept, reported changes in food and physical activity behaviors, empowerment of children and parents, children's self-esteem, and implementation of resiliency concepts. Emergent themes included family responses and issues for multihousehold families.

\section{Results}

\section{Recruitment and Study Population}

Recruitment occurred from mid-December 2005 through February 2006 through a mix of community outreach efforts (flyers, posters, newspaper advertisements, newspaper articles) encouraging interested families to contact us. Seventy-five families responded to our outreach by contacting our office or leaving phone messages, and 35 subsequently consented and were randomized to the study. Two families were unable to attend sessions, but the children received nearly all the measurements and are included in all analyses. The remaining 30 children attended $75 \%$ of class sessions, on average. The data completion rate was $95 \%$. Details are provided in Figure 1.

The baseline characteristics of the study population are shown in Table 2. The groups were balanced on most characteristics. The group size for cohort 1 was 15 boys and girls and for cohort 2 was 17 boys and girls.

\section{Growth and Questionnaire Outcomes}

Analyses of growth data are shown in Table 3 and in Figures 2 and 3. The intervention effects are shown as regression coefficients, where the outcome was measured at the end of a 3-month interval (as shown in Figures 2 and 3), and the explanatory variable was time on intervention (in 3 -month units). The primary outcome BMI $z$ score showed a significant beneficial intervention effect of $-0.046(P=.017)$ per 3 -month interval, and weight $z$ score was $-0.29(P=.09)$ per 3 -month interval. Again, in terms of 3-month changes, the intervention effect was estimated to be -0.34 $\mathrm{kg} / \mathrm{m}^{2}(P=.025)$ for BMI, in light of a natural growth rate of $0.51 \mathrm{~kg} / \mathrm{m}^{2}$, and $-0.64 \mathrm{~kg}(P=.053)$ for weight relative to natural growth of $2.30 \mathrm{~kg}$.

In addition, height also showed an intervention effect of $+0.59 \mathrm{~cm}$ per 3 months $(2.36 \mathrm{~cm} /$ year [graph not shown]; $P=.06$ ). The intervention effect on percentage body fat (Tanita) was generally consistent with the other results but did not achieve statistical significance. The declines in weight and BMI clearly were associated with the lagged intervention design (Figures 2 and 3). The graphical results suggest that the intervention effects lasted for at least 6 months beyond the end of the intervention; in wave 1 with extended followup, the intervention effects were seen to last for 12 months.

For physical activity, there was a large positive estimated intervention effect for increasing activities with high METs, and a similarly large reduction effect for activities with low METs; activities with medium METs remained essentially unchanged. While none of these activity group changes was statistically significant alone, the net shift of activity from the low METs group to the high METs group had an intervention effect of 2.84 (SDE, 1.36; $P=.037$ ). The time-trend effects for high and low METs did not approach significance. 
Table 2. Baseline anthropometrics and demographics

\begin{tabular}{|c|c|c|c|c|c|}
\hline \multirow[b]{2}{*}{ Characteristic } & \multicolumn{2}{|c|}{ March } & \multicolumn{2}{|c|}{ September } & \multirow[b]{2}{*}{ Total } \\
\hline & Boys & Girls & Boys & Girls & \\
\hline Sample size, $\mathrm{n}$ & 7 & 8 & 9 & 8 & 32 \\
\hline Age (yrs) & $9.7 \pm 0.4$ & $9.7 \pm 0.8$ & $9.6 \pm 0.6$ & $9.3 \pm 0.6$ & $9.6 \pm 0.6$ \\
\hline Weight (kg) & $56.0 \pm 9.1$ & $53.1 \pm 8.8$ & $56.8 \pm 15.6$ & $58.8 \pm 15.9$ & $56.2 \pm 12.6$ \\
\hline Weight/age $Z^{*}$ & $2.35 \pm 0.44$ & $2.10 \pm 0.58$ & $2.31 \pm 0.70$ & $2.46 \pm 0.71$ & $2.31 \pm 0.61$ \\
\hline Height (cm) & $144.1 \pm 4.1$ & $143.4 \pm 5.7$ & $146.4 \pm 8.0$ & $146.0 \pm 10.1$ & $145.1 \pm 7.2$ \\
\hline Height/age $Z^{*}$ & $1.07 \pm 0.62$ & $1.03 \pm 0.69$ & $1.50 \pm 0.04$ & $1.67 \pm 0.06$ & - \\
\hline $\mathrm{BMI}\left(\mathrm{kg} / \mathrm{m}^{2}\right)$ & $26.9 \pm 3.6$ & $25.8 \pm 4.0$ & $26.3 \pm 6.2$ & $27.5 \pm 6.8$ & $26.6 \pm 5.2$ \\
\hline BMI/age $Z^{*}$ & $2.19 \pm 0.33$ & $2.00 \pm 0.45$ & $2.07 \pm 0.42$ & $2.11 \pm 0.53$ & $2.09 \pm 0.43$ \\
\hline Body fat $(\%)^{\dagger}$ & $41.3 \pm 14.3$ & $36.9 \pm 5.3$ & $35.4 \pm 9.5$ & $39.4 \pm 8.8$ & $38.1 \pm 9.6$ \\
\hline \multicolumn{6}{|l|}{ Mother's education (n) } \\
\hline High school/GED & \multicolumn{2}{|c|}{3} & \multicolumn{2}{|c|}{0} & 3 \\
\hline Some college or vocational training & \multicolumn{2}{|c|}{4} & \multicolumn{2}{|c|}{5} & 9 \\
\hline College degree & \multicolumn{2}{|c|}{5} & \multicolumn{2}{|c|}{2} & 7 \\
\hline$>$ College & \multicolumn{2}{|c|}{2} & \multicolumn{2}{|c|}{5} & 7 \\
\hline \multicolumn{6}{|l|}{ Father's education (n) } \\
\hline$<$ High school/GED & \multicolumn{2}{|c|}{4} & \multicolumn{2}{|c|}{3} & 7 \\
\hline Some college or vocational training & \multicolumn{2}{|c|}{5} & \multicolumn{2}{|c|}{4} & 9 \\
\hline College degree & \multicolumn{2}{|c|}{3} & \multicolumn{2}{|c|}{2} & 5 \\
\hline$>$ College & \multicolumn{2}{|c|}{2} & \multicolumn{2}{|c|}{3} & 5 \\
\hline \multicolumn{6}{|l|}{ Family income, \$ (n) } \\
\hline$<50,000$ & \multicolumn{2}{|c|}{6} & \multicolumn{2}{|c|}{4} & 10 \\
\hline$\geq 50,000-100,000$ & \multicolumn{2}{|c|}{4} & \multicolumn{2}{|c|}{4} & 8 \\
\hline$>100,000$ & \multicolumn{2}{|c|}{3} & \multicolumn{2}{|c|}{4} & 7 \\
\hline \multicolumn{6}{|l|}{ Ethnicity (n) } \\
\hline American Indian/Alaska Native & \multicolumn{2}{|c|}{0} & & & 1 \\
\hline Asian/Pacific Islander & & & & & 3 \\
\hline Hispanic & & & & & 7 \\
\hline Non-Hispanic white & & & & & 21 \\
\hline
\end{tabular}

Values provided as mean \pm standard deviation unless otherwise indicated.

${ }^{*}$ Centers for Disease Control and Prevention.

${ }^{\dagger}$ Tanita.

\section{Interview Results}

Interviews 12 to 18 months beyond the intervention suggest that many behavior changes were lasting. Children were queried about specific ongoing changes in food choices. Table 4 presents their most frequent answers. Children who avoided vegetables were willingly eating them. Many children who primarily drank soda at baseline now predominantly drank water. Some children who were sedentary now enjoyed physical activity and participated regularly in organized activities. Parents reported that girls were growing into lower BMIs. Although parents acknowledged struggling with Choices topics, they felt their roles were more clearly defined. Parents reported being enthusiastic about making changes; 1 year after the intervention, they requested a booster session for additional support. Interviews 18 to 24 months after the intervention revealed that more than half the families maintained some new behaviors and about half the children were reported to be on different growth and physical activity trajectories.

Table 5 provides quotations from the qualitative interviews. The first quotations illustrate how the information from the Choices sessions was woven into families' daily routines. The children's quotes suggest their sense of self-efficacy around food and activity. The parents' comments similarly show how the Choices experience shifted family dynamics. Parent 10 illustrates how parents also benefited from the resilience approach by having a forum for sharing beliefs and support to try new approaches. Their involvement provided tools to enhance their parenting skills. 
Table 3. Regression Effects* of CHOICES Intervention

\begin{tabular}{lcc}
\hline Outcome $^{\dagger}$ & Intervention effect & \\
\hline$Z$ score & & $P^{\S}$ \\
BMI & $-0.046(0.022)$ & .017 \\
Weight & $-0.029(0.022)$ & .090 \\
Height & $0.041(0.027)$ & .127 \\
BMI $\left(\mathrm{kg} / \mathrm{m}^{2}\right)$ & $-0.34(0.17)$ & .025 \\
Weight $(\mathrm{kg})$ & $-0.64(0.39)$ & .053 \\
Height $(\mathrm{cm})$ & $0.59(0.21)$ & .006 \\
METs & & .084 \\
Low & $-1.04(0.60)$ & .904 \\
Medium & $0.13(1.08)$ & .197 \\
High & $1.82(1.42)$ & \\
\hline
\end{tabular}

*The other variables in the equation were baseline value, male indicator, and growth trend.

${ }^{\dagger} \mathrm{N}=32$ for weight, body mass index, and height; $\mathrm{n}=22$ for physical activity.

${ }^{\ddagger}$ Per 3-month period after intervention.

${ }^{\S}$ One-sided for weight and body mass index (BMI); 2-sided for all other variables.

"Shift from low metabolic equivalents (METs) to high METs significant at $P=.037$; see text for details.

SDE, standard deviation of the estimate (sometimes called standard error).

Other quotes in Table 5 exemplify the integration of the resilience component. As families increased knowledge about nutrition and activity, they enhanced their flexibility to change in these areas. Several enrolled families experienced separation or divorce. The Choices sessions provided time for expression and processing of family conflicts. In some divorced families, the information was used by both parents, as illustrated in quotes from parents 6 and 7. For other families, the project was unable to function across family conflicts. Components of the resilience models were designed to ease the stigma of being overweight by teaching children that they could respond differently in challenging situations. Examples in the lessons were drawn from daily life as well as from food and activity situations. The reports from parents 8 and 9 suggest that this was successful for the children.

\section{Discussion}

This intervention, using a resilience approach, showed that children who participated became less sedentary and decreased their BMI. The intervention model was well accepted by parents and children, and interviews after the intervention demonstrated sustained changes.
Overweight children are less physically active than their nonoverweight peers, ${ }^{18}$ and this tracks into adulthood. ${ }^{19}$ Our physical activity intervention (ie, television turnoff, pedometers, activity passport, toys) was successful in decreasing sedentary activities and possibly increasing high-intensity activities. The 9-month duration of the effect beyond the intervention is consistent with a recent systematic review of childhood physical activity interventions. $^{20}$

Unlike interventions that use natural social groups such as clubs or schools, the Choices project brought together children sharing common issues who had never met. Children were among others with similar body habitus and struggling with similar issues of self-esteem.

The parent quotes suggest the Choices model intervention follows an approach suggested by Ludwig, ${ }^{21}$ in that a key parenting practice applicable to all ages is to create a protective environment in the home that applies equally to everyone to avoid stigmatizing obese children and support the health of the whole family. The model was adaptable, recognizing that not all members of the families were overweight. The program focused on building life skills appropriate to all family members.

The foundation of the model empowered parents and children by providing a nonjudgmental framework to make lifelong changes. The model acknowledged children as important agents for change and allowed them to make educated choices not driven by rebellion or conflict. It built on the observations of Epstein et $\mathrm{al}^{22-26}$ that children with the most control over their physical activity in the intervention were the most active years later and carried that thread forward about food and beverage choices. Prior obesity interventions have restricted one macronutrient or provided food rules or mnemonics without empowering children explicitly. For example, a study by Kalarchian et $\mathrm{al}^{27}$ introduced a "Stoplight Eating Plan" where foods were assigned red, yellow, or green for unhealthy, not necessary for health, and healthy foods, respectively. The control group also received this model but did not receive the repeated counseling visits. Although weight loss was seen initially in the study group, these losses were not maintained beyond 12 months after the intervention. In contrast, Choices avoided judgmental food labeling. The qualitative data after intervention suggest that many families 
Figure 2. Body mass index (BMI) and BMI $z$ score. Top: light dashed line represents the predicted increase in BMI if the children were to continue at the same Centers for Disease Control and Prevention $z$ score (percentile). Bottom: The BMI age-specific $z$ score. In both panels, the beavy dashed line represents the intervention periods, and the dots are the 3 measurements points after the intervention for each group.
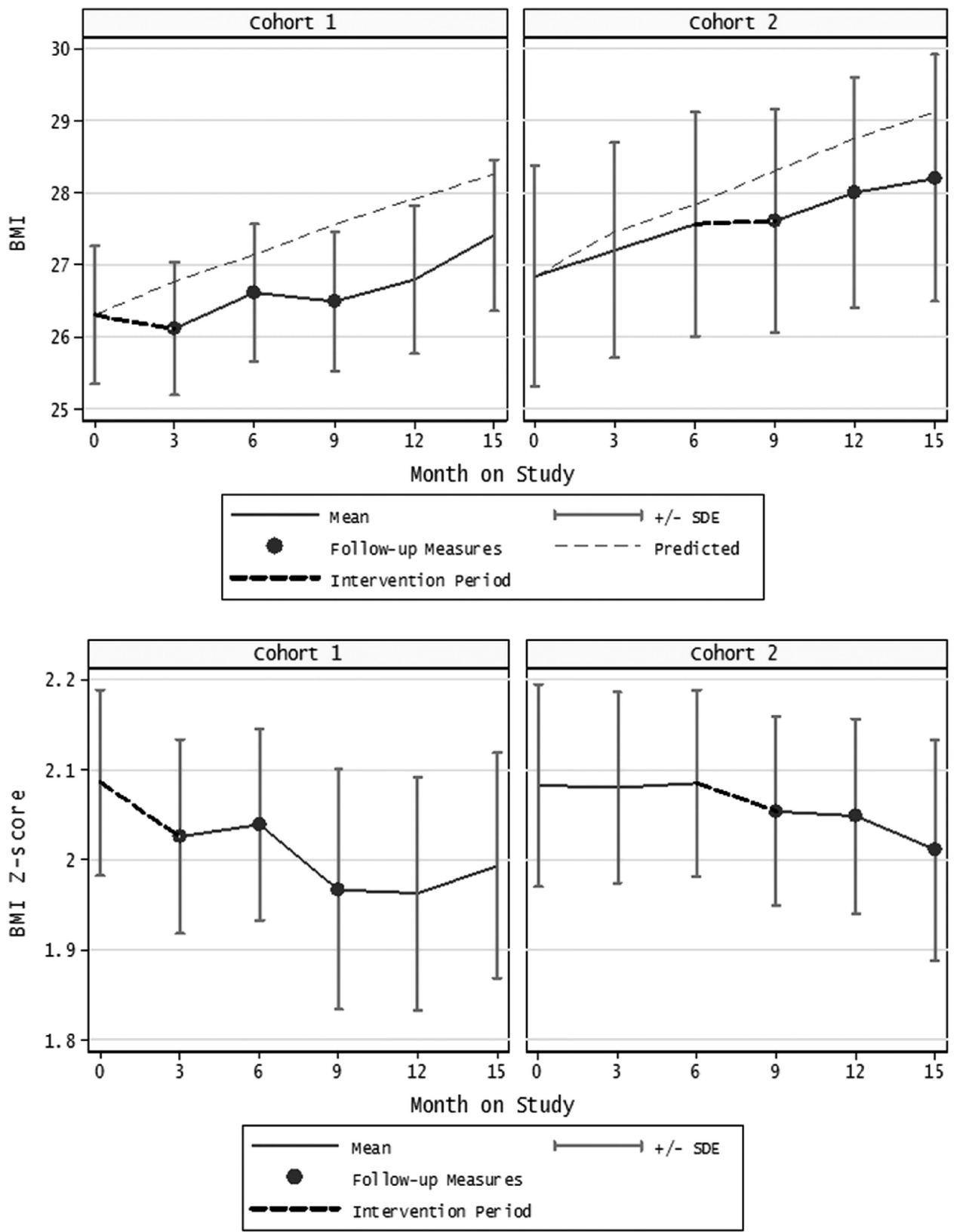

continued to maintain some of the changes. It is possible that the empowerment approach coupled with simple lifestyle changes contributed to the long-term endurance of some of the effects. The children enthusiastically attended the sessions and were often the catalyst motivating their parents to be punctual for the sessions, to be diligent about wearing their pedometers, and to be compliant in turning off the television during television turnoff week.

In contrast to an ongoing study involving only parents of overweight children, ${ }^{28}$ our intervention targeted both parents and children. Although we were concerned that empowering children might challenge parental control, the qualitative data support that the model instead clarifies the parental 
Figure 3. Weight and weight for age $z$ score. Top: The dashed line represents the predicted weight increase if the children were to continue at the same Centers for Disease Control and Prevention $z$ score (percentile). Bottom:

The age-specific $z$ score for weight. In both panels, the beavy dashed line represents the intervention periods, and the dots are the 3 measurement points after the intervention.


role as controlling the food supply and providing opportunities for physical activity and the child's role as making informed choices in a supportive environment.

The resilience model was an excellent match for this empowerment perspective. Parents and children beginning the program found themselves locked in difficult situations, feeling they had tried everything but without success. The voluminous literature on the pessimistic explanatory style has shown it to be a precursor to helplessness, hopelessness, and depression because it constricts the pessimist's ability to generate creative solutions to old problems. ${ }^{29-32}$ The resilience components worked to circumvent pessimism in 2 ways. First, explicit techniques to avoid pessimistic explanatory styles were learned and reinforced. Second, offering creative lifestyle "choices" modeled the gener- 
Table 4. Counts of Children's Spontaneous Comments About Changes in Food Choices

\begin{tabular}{lc}
\hline Food-related choices & N \\
\hline Smaller portions & 9 \\
Drinking more water & 7 \\
Eating healthier in general & 6 \\
Drinking less soda & 4 \\
Eating less fast food & 4 \\
Making better choices when eating out & 3 \\
Trying new fruits and vegetables & 3 \\
Snacking less between meals, and improving snack choices & 3 \\
\hline
\end{tabular}

ation of new problem-solving possibilities that would otherwise be difficult for the pessimist to generate. The model gave participants permission to become flexible and change their response to their child's behavior around eating and activity. Even the most authoritarian parents began to relinquish unnecessary levels of control by week 8 as they witnessed their children making reasonable choices.

\section{Limitations}

Given the need for rapid recruitment to fulfill research goals, a majority of families were recruited from the community rather than clinical sites. This may indicate obstacles unique to our clinical sites but may point to more general issues for recruitment within clinic populations. Possible issues include (1) healthy children are seen infrequently, (2) other issues often take precedence over discussion of overweight, (3) hectic family lives, (4) delayed wait times for beginning groups, and (5) lack of understanding that overweight is a health problem among children. In addition, many of the subjects in the study were from non-Hispanic white backgrounds. This, along with the small study size, limits the generalizability of the conclusions.

\section{Table 5. Representative Quotations from Qualitative Interviews}
Implementation of Parent 1: "They said, 'This is not what you have to do, this is the way it is. If you choose to do this, it leads the Choices to some ramifications. Do you want this or not? It's up to you.' ...It was constantly stressed that we're model not telling you what to do...we're just showing you, giving you bits of information so that you can make choices.... As a parent, that's exactly what I try and do with [my daughter]."
Parent 2: “...When [child's name] will say to me, 'Can I have this or that?' what I try and say is it's your body, it's your choice what you put into your body, you are in control or what goes into your body, you know, and so I try and evoke...I think that the name Choices for the program is a great name."
Parent 3: "I thought Choices was great...good lifestyle information that everyone Can benefit from, not just people that are struggling with weight issues..."
Interviewer: So you like going outside a lot, and you got into the program to learn about that? Child 1: Yeah, and to learn how I can get fit, just be more confident with who I am, and just make better choices.
Child 2: [Making better food choices] made me...feel better, like, on the holidays, that I don't eat as much. And that I'm watching over myself, instead of just my parents watching over me. And it has made me feel good that I have gotten more active and stuff like that.
Parent 4: “...Before I came to Choices classes I had all those problems, a lot of the conflicts for food, [child] wants some bad foods, as a parent I try to be nice and then...sometimes I get angry, and behave angry, all those...we have family conflicts, and then when I came to Choices classes and talked to other parents, I realized it's not only my problem, it's everyone's problem. We feel like friends, even though we only met a couple of times, we already feel the same way."

Resilience

Parent 5: "My wife was very...supportive, she liked us coming to the Choices project because she's also concerned about [child]'s health, and she knows that all those pamphlets, all [that] information, that I bring from the Choices project, she takes a look at the reading materials."

Parent 6: "Everyday in the beginning when we would come to the class, [the nutritionist] would have some kind of low-calorie snack, which was good...now I'm putting more vegetables in his lunch."

Parent 7: "Her mother tends to like chicken nuggets and Easy Macs, but I know she took information back, and I noticed because Monday she packs a lunch for [child's name], [whispering] so I always check, and there actually gets to some fresh fruit in there and vegetables now."

Parent 8: “...When I am with [child's name] I always try and encourage her, you know, watch her portions, think about what you are putting in your body, drink more water, and I don't think that a lot of that is happening when she is with her mom...."

Parent 9: "...Some kids had been teasing her at school before we got here, and so she was very selfconscious.... And then, the other thing is that I think the class gave her a little more confidence..."

Parent 10: "I think seeing other kids heavy helped him accept that it's okay to be heavier because [before] he would wear sweatshirts in May when it was like 95 degrees outside...and he doesn't do that anymore, this year he is not wearing his hoodie." 
More objective outcome measures could have been collected, including data on step counts derived from pedometers. We recognize the bias inherent in the use of self-reported nutrition and activity assessment tools.

\section{Clinical Implications}

This "proof of concept" study was designed to test the efficacy of the group office visit model in reducing children's weight and increasing physical activity. Since we conducted the study at a family medicine residency training site, we included family medicine residents to facilitate the children's groups. However, replication in a community setting needs further exploration. Groups could be conducted with 1 physician and 1 or 2 medical assistants/nurses, or boys/ parents groups could be scheduled at different time than girls/parents groups to reduce the number of facilitators required.

Another consideration is provider compensation. In this model physicians see a similar number of patients per hour compared with routine office visits; this makes it economically feasible and cost neutral at the clinic level. In addition, the national emphasis on childhood obesity may provide new incentives for intervention programs targeting overweight children.

\section{Conclusion}

Our study offers a novel approach for family physicians to empower parents and children in a group office setting. The visits incorporate the concepts of "choices" and "resiliency," nutrition and physical activity messages emphasizing that energy balance is a lifelong issue. The Choices model produced positive changes in participants' lifestyles that endured beyond the time frame of the intervention. The long-term relationship between patients and family physicians may provide the optimal venue for continuing support of families challenged by issues of obesity and maintenance of healthy lifestyle changes, and these results suggest that this intervention warrants a larger clinical trial in a clinical setting.

\section{References}

1. Flegal KM, Carroll MD, Ogden CL, Curtin LR. Prevalence and trends in obesity among US adults, 1999-2008. JAMA 2010;303:235-41.

2. Ogden CL, Carroll MD. Prevalence of high body mass index in US children and adolescents, 20072008. JAMA 2010;303:242-9.
3. Whitaker RC, Wright JA, Pepe MS, Seidel KD, Dietz WH. Predicting obesity in young adulthood from childhood and parental obesity. N Engl J Med 1997;37:869-73.

4. Serdula MK, Ivery D, Coates RJ, Freedman DS, Williamson DF, Byers T. Do obese children become obese adults? A review of the literature. Prev Med 1993;22:167-77.

5. Wolin KY, Carson K. Obesity and Cancer. Oncologist 2010;15:556-65.

6. Birch LL, Davison KK. Family environmental factors influencing the developing behavioral controls of food intake and childhood overweight. Pediatr Clin North Am 2001;48:893-907.

7. White House Task Force on Childhood Obesity report to the President. Let's Move. Available from: http://www. letsmove.gov/white-house-task-force-childhood-obesityreport-president. Accessed January 9, 2012.

8. Plourde G. Preventing and managing pediatric obesity. Recommendations for family physicians. Can Fam Physician 2006;52:322-8.

9. Fisher JO, Birch LL. Restricting access to palatable foods affects children's behavioral response, food selection, and intake. Am J Clin Nutr 1999;69:1264-72.

10. Golan M, Crow S. Parents are key players in the prevention and treatment of weight-related problems. Nutr Rev 2004:62:39-50.

11. Baranowski T, Cullen KW, Nicklas T, et al. Schoolbased obesity prevention: a blueprint for taming the epidemic. Am J Health Behav 2002;26:486-93.

12. Hingle M, O'Connor T, Dave JM, Baranowski T. Parental involvement in interventions to improve child dietary intake: a systematic review. Prev Med 2010;51:103-11.

13. Robinson TN. Reducing children's television viewing to prevent obesity: a randomized controlled trial. JAMA 1999;282:1561-7.

14. Reivich K, Shatte A. The Resilience Factor. NY: Broadway Books; 2002.

15. Aickin M. A simulation study of the validity and efficiency of design-adaptive allocation to two groups in the regression situation. Int J Biostat 2009;5:Article 19.

16. Centers for Disease Control and Prevention. Percentile data files with LMS values. Available from: http:// cdc.gov/growthcharts/percentile_data_files.htm. Accessed January 5, 2013.

17. Going SB, Levin S, Harrell J, et al. Physical activity assessment in American Indian schoolchildren in the Pathways study. Am J Clin Nutr 1999;69(4 Suppl): 788S-95S.

18. Andersen RE, Crespo CJ, Bartlett SJ. Relationship of physical activity and television watching with body weight and level of fatness among children. Results from the Third National Health and Nutrition Examination Survey. JAMA 1998;279:938-42.

19. Gordon-Larsen P, Nelson MC, Popkin BM. Longitudinal physical activity and sedentary behavior 
trends: adolescence to adulthood. Am J Prev Med 2004;27:277-83.

20. Savoye M, Shaw M, Dziura J, et al. Effects of a weight management program on body composition and metabolic parameters in overweight children: a randomized controlled trial. JAMA. 2007;297:2697-704.

21. Ludwig DS. Weight loss strategies for adolescents. JAMA 2012;37:498-508.

22. Epstein LH, Valoski A, McCurley J. Effect of weight loss by obese children on long-term growth. Am J Dis Child 1993;147:1076-80.

23. Epstein LH, Valoski A, Wing RR, McCurley J. Tenyear outcomes of behavioral family-based treatment for childhood obesity. Health Psychol 1994;13:373-83.

24. Epstein LH, Wing RR, Koeske R, Valoski A. Familybased behavioral weight control in obese young children. J Am Diet Assoc 1986;86:481-4.

25. Epstein LH, Kuller LH, Wing RR, Valoski A, McCurley J. The effect of weight control on lipid changes in obese children. Am J Dis Child 1989;143:454-7.

26. Epstein LH, Valoski A, Wing RR, McCurley J. Tenyear follow-up of behavioral family-based treatment for obese children. JAMA 1990;264:2519-23.

27. Kalarchian MA, Levine MD, Arslanian SA, et al. Family-based treatment of severe pediatric obesity: a randomized controlled trial. Pediatrics 2009;124: $1060-8$.

28. Resnicow K, McMaster F. Study design and baseline description of the BMI (2) trial: reducing paediatric obesity in primary care practices. Pediat Obes 2012; 7:3-15.

29. Seligman MEP, Nolen-Hoeksema S. Explanatory style and depression. In: Magnusson D, Ohman A, eds. Psychopathology: An Interactional Perspective. New York: Academic Press; 1987:125-39.

30. Sweeney PD, Anderson K, Bailey S. Attributional style in depression a meta-analytic review. J Pers Soc Psychol 1986;50:974-91.

31. Abramson LY, Metalsky FI, Alloy LB. Hopelessness depression: a theory based subtype of depression. Psycho Rev 1989;96:358-72.

32. Robins CJ, Hayes AM. The role of causal attributions in the prediction of depression. In Buchanan GM, Seligman MEP, eds. Explanatory Style. Hillsdale, NJ: Lawrence Erlbaum Associates; 1995:71-98.

\section{Appendix}

\section{Lesson 1: What is Choices?}

\section{Objectives}

Participants will increase their physical activity by:

1. Identify the key elements of the Choices program, including nutrition education, physical activity, and developing resiliency skills.

2. Use a pedometer as a self-monitoring technique to establish a physical activity baseline.

3. Learn the value of family support during the program.

\begin{tabular}{|c|c|c|}
\hline $\begin{array}{l}\text { Suggested Time } \\
\text { in Class } 1\end{array}$ & Activities & Materials Needed \\
\hline $20 \mathrm{~min}$ & I. Check-in, sharing, snacks, and group rules & - Snacks, poster board for group rules \\
\hline \multirow[t]{3}{*}{$20 \mathrm{~min}$} & II. What is CHOICES? & - Handout \\
\hline & What is family support? & \\
\hline & What is safety when active? & - General safety guidelines \\
\hline $30 \mathrm{~min}$ & III. Pedometer introduction, logging, pedometer practice & $\begin{array}{l}\text { - Pedometers } \\
\text { - Lifestyle Activity Estimate sheets }\end{array}$ \\
\hline $5-10 \mathrm{~min}$ & IV. Lesson summary and next week's home activity assignment & - Pedometer Log sheet \\
\hline
\end{tabular}

